\title{
УСТАНОВЛЕНИЕ И ИССЛЕДОВАНИЕ ФАКТИЧЕСКИХ ОБСТОЯТЕЛЬСТВ В КОНСТИТУЦИОННОМ СУДОПРОИЗВОДСТВЕ: ПРОБЛЕМЫ ТЕОРИИ И ПРАКТИКИ
}

\begin{abstract}
Аннотация: Предметом исследования являются правоотношения, возникающие в сфере конституционного судопроизводства, при установлении и исследовании фактических обстоятельств дела. В сравнительном плане показан объем фактических обстоятельств, исследуемых на различных этапах конституционного правосудия, раскрыта процессуальная специфика их установления в зависимости от организационной формы конституичонного судопроизводства и особенностей конкретного полномочия Конституционного Суда Российской Федерации. Подчеркнуты отличия конституционного судопроизводства в части, касаюшейся установления $и$ исследования фактических обстоятельств, от иных процессуальньхх форм осуществления судебной власти. $B$ проиессе исследования использовались общенаучные (диалектический, системньй) и специальнье (сравнительно-правовой, формально-юридический) методы, что позволило раскрыть механизм установления фактических обстоятельств в конституционном судопроизводстве, показать их роль в достижении иелей правосудия. На основе анализа законодательства и судебной практики раскрыта вспомогательная и субсидиарная роль фактических обстоятельств в процессе рассмотрения дела, подведомственного Конституционному Суду. С учетом перспектив развития правосудия в России показаны процессуальные средства, обеспечивающие установление этих обстоятельств, отмечены наиболее значимые современные тенденции, касающиеся влияния вопроса о необходимости исследования фактических обстоятельств на определение компетенции органа конституционного контроля.
\end{abstract}

Ключевые слова: Правосудие, полномочия, норма, конституциия, запрос, законодательство, фактические обстоятельства, суд, судопроизводство, проиесс.

Abstract: The subject of this research is the legal relations, arising in the sphere of constitutional legal proceedings in establishing and researching the factual circumstances of the case. In comparative terms the author shows the amount of the factual circumstances, researched at various stages of the constitutional justice, and reveals the procedural specifics of their establishment, depending on the organizational form of constitutional legal proceedings and features of the concrete power of the Constitutional Court of the Russian Federation. Emphasis is made on the difference between the constitutional legal proceedings in respect to the establishment and research of the factual circumstances and other procedural forms of the judicial power. Based on an analysis of the legislation and judicial practice the author determines an auxiliary and subsidiary role of the factual circumstances in the course of the proceedings, subordinate to the Constitutional Court. Taking into account the prospects of development of justice in Russia the author demonstrates the procedural means for the establishment of these circumstances, highlights the most significant current trends regarding the impact of the need to research the factual circumstances to determine the competence of the body of constitutional control.

Keywords: Justice, powers, norm, constitution, inquiry, legislation, factual circumstances, court, proceedings, process.

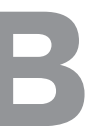

соответствии с Конституцией Российской Федерации (ч. 2 ст. 118) судебная власть в России осуществляется посредством конституционного, гражданского, административного и уголовного судопроизводства. Установление и исследование фактических обстоятельств, т.е. событий, действий, влекущих возникновение, изменение, прекращение правоотношений, имеет ключевое значение при рассмотрении судами гражданских, уголовных, и, как правило, административных дел $[5,10]$. Это обусловлено, прежде всего, спецификой механизма судебного правоприменения: осуществив обоснованный выбор норм законодательства, регулирующих соответствующие общественные отношения, суд обязан достоверно установить юридические факты, указанные в содержании соответствующих норм и имеющие, таким образом, правовые последствия и значение для рассматриваемого дела. Это позволяет обеспечить точное применение нормативных положений к установленным обстоятельствам, и, в конечном счете, принять законный и обоснованный судеб- 
ный акт, являющийся, по общему правилу, правоприменительным решением [1].

Конституционное судопроизводство как процессуальная форма осуществления судебной власти обладает некоторыми особенностями. Целями конституционного судопроизводства являются защита основ конституционного строя, основных прав и свобод человека и гражданина, обеспечение верховенства и прямого действия Конституции на всей территории Российской Федерации (ч. 1 ст. 3 Федерального конституционного закона от 21 июля 1994 года № 1-ФК3 «О Конституционном Суде Российской Федерации»). Полномочия, которыми наделен Конституционный Суд, связаны преимущественно с проверкой конституционности законов и иных нормативных правовых актов, разрешением споров о принадлежности того или иного полномочия органу государственной власти, толкованием норм Конституции. Все относящиеся к его ведению дела возникают из публично-правовых отношений. Вопросы, являющиеся предметом рассмотрения Конституционного Суда, носят общий характер: как правило, они затрагивают права и законные интересы неопределенного круга лиц, а не только заявителей. Это обусловливает и юридическую силу решений Конституционного Суда, в частности, их общеобязательный характер: данные решения в перспективном плане обладают нормативной значимостью и вне той правоприменительной ситуации, в связи с которой последовало обращение в Конституционный Суд, а также в отношении и тех субъектов, которые не являлись заявителями в Суде. Формулируемые в решениях Конституционного Суда правовые позиции в известной мере ограничивают свободу усмотрения законодателя, должны учитываться им в правотворческой деятельности, но в тоже время обладают и юридической «самодостаточностью», непосредственно применяются судами общей юрисдикции и арбитражными судами при разрешении подведомственных им дел, в т.ч. при истолковании норм текущего законодательства [8].

Исходя из этого, конституционное судопроизводство, в отличие от гражданского, является в первую очередь средством обеспечения публичного правопорядка $[6,7]$. Защита субъективных прав и законных интересов конкретных физических и юридических лиц, даже если производство в Конституционном Суде возбуждено в связи с их обращениями, осуществляется в конечном итоге посредством реализации иных форм судебной власти. Конституционный Суд лишь устраняет нормативные препятствия для такой защиты, что делает возможным последующее восстановление нарушенных прав этих лиц судами общей юрисдикции, арбитражными судами. Эти обстоятельства обусловливают процессуальную специфику конституционного судопроизводства, которая проявляется, помимо прочего, в том, что в соответствии с ч. 3 и 4 ст. 3 Федерального конституционного закона «О Конституционном Суде Российской Федерации» Конституционный Суд решает исключительно вопросы права; при осуществлении конституционного судопроизводства он воздерживается от установления и исследования фактических обстоятельств во всех случаях, когда это входит в компетенцию других судов или иных органов. Таким образом, Конституционный Суд при реализации своих юрисдикционных полномочий исследует, прежде всего, свойства проверяемого нормативного правового акта, устанавливает полномочия издавшего его органа власти, соотносит содержание норм данного акта с положениями Конституции Российской Федерации (что, в свою очередь, требует системного истолкования последних), т.е. проводит оценку конституционности проверяемого акта.

Отметим, что запрет на установление и исследование фактических обстоятельств в конституционном судопроизводстве не носит абсолютного характера. Он установлен, прежде всего, в целях разграничения полномочий Конституционного Суда и иных судебных органов, имея в виду недопустимость «подмены» конституционным судопроизводством других форм судебной власти и превращения Конституционного Суда в своего рода экстраординарную инстанцию по отношению к судам общей юрисдикции и арбитражным судам [4]. Но это нисколько не умаляет того, что ключевую роль в доказывании в конституционном судопроизводстве, как правило, играют не сведения о фактических обстоятельствах, а правовые позиции, формулируемые сторонами, а затем и Конституционным Судом в итоговом решении. В основе этих позиций лежат правовые аргументы, доводы, основанные на толковании конституционных принципов, норм, положений оспариваемых актов в системном единстве с нормами и принципами международного права, правоприменительной практикой, позициями Конституционного Суда и международных судебных органов. Сами по себе аргументы, доводы, а значит, и правовые позиции в целом являются результатом мыслительной деятельности участников конституционного судопроизводства. Присущий данной форме судебной власти принцип состязательности предполагает помимо прочего, что Конституционный Суд осуществляет правосудие в условиях конкуренции различных правовых позиций, формулируемых сторонами по делу. 
В пользу этой точки зрения свидетельствует содержание следующих норм Федерального конституционного закона «О Конституционном Суде Российской Федерации»: ст. 35, в соответствии с которой «стороны пользуются равными правами и возможностями по отстаиванию своей позиции на основе состязательности в заседании Конституционного Суда Российской Федерации»; п. 8 ч. 2 ст. 37, предусматривающий императивное требование, в силу которого в обращении в Конституционный Суд обязательно должна содержаться «позиция заявителя по поставленному им вопросу и ее правовое обоснование со ссылкой на соответствующие нормы Конституции Российской Федерации»; ч. 3 ст. 53, согласно которой «стороны и их представители вправе.. излагать свою позицию по делу»; ч. 1 ст. 62, предусматривающая, что «председательствующий в заседании предлагает сторонам дать пояснения по существу рассматриваемого вопроса и привести правовые аргументы в обоснование своей позиции» (данная норма, таким образом, четко указывает на то, что в основе правовой позиции лежат именно правовые аргументы) (курсив мой - О.Б.).

Что же касается фактических обстоятельств, то их значение в конституционном судопроизводстве носит иной характер, нежели применительно к другим формам осуществления судебной власти [9]. В конституционном судебном процессе установление фактических обстоятельств играет, как правило, вспомогательную и субсидиарную роль, т.е. является лишь средством дополнительного обоснования сторонами своей правовой позиции и допустимо лишь постольку, поскольку не отнесено к компетенции других судов или иных органов.

Стороны и иные участники конституционного судопроизводства в установленном порядке представляют сведения о фактических обстоятельствах, подлежащих исследованию в порядке конституционного судопроизводства. Кроме того, Федеральный конституционный закон «О Конституционном Суде Российской Федерации», учитывая публично-правовой характер разрешаемых дел, предусматривает, что Конституционный Суд вправе проявлять активную роль в установлении этих обстоятельств как на стадии подготовки дела к слушанию (ч. 2 ст. 49), так и в процессе его рассмотрения (ст. 50).

Характеризуя объем фактических обстоятельств, подлежащих установлению при рассмотрении дела в Конституционном Суде, следует отметить, что его необходимо дифференцировать в зависимости от: предназначения сведений о юридических фактах в общей структуре доказывания и специфики конкретного полномочия Суда.
Прежде всего, выделим те юридические факты, с наличием которых связано право на обращение в Конституичионный Суд, которые, в свою очередь, можно разделить на четыре группы.

Первую группу составляют те факты, первичное установление которых отнесено к компетенции Секретариата Конституционного Суда (ч. 2 ст. 40 Федерального конституционного закона «О Конституционном Суде Российской Федерации»). К таковым относятся факты: явного соблюдения или несоблюдения правил подведомственности; соответствия обращения требованиям к его форме; обладания заявителем правом на обращение; уплаты установленной государственной пошлины; соблюдения годичного срока, предусмотренного для обращения с жалобой на нарушение конституционных прав и свобод граждан. По итогам установления данных фактов Секретариат вправе уведомить заявителя о несоответствии его обращения требованиям Федерального конституционного закона «О Конституционном Суде Российской Федерации».

Ко второй группе фактов следует отнести те, установление которых на стадии принятия обращения к рассмотрению осуществляется безотносительно к особенностям конкретного полномочия Конституционного Суда (ст. 43 Федерального конституционного закона «О Конституционном Суде Российской Федерации»). К ним относятся факты: соблюдения правил подведомственности; наличия или отсутствия по предмету обращения ранее вынесенного постановления Конституционного Суда, сохраняющего свою силу; действия оспариваемого акта или продолжения его применения к правоотношениям, возникшим в период его действия, и др. В зависимости от характера данных фактов Конституционным Судом решается вопрос о принятии обращения к рассмотрению или об отказе в этом.

К третьей группе относятся факты, обусловливающие выбор организационной формы конституционного судопроизводства. Установление Конституционным Судом фактов того, что по предмету обращения ранее уже формулировались правовые позиции, совокупность которых достаточна для рассмотрения дела по существу, и проведение слушания не является необходимым для обеспечения прав сторон, является основанием для рассмотрения дела без проведения слушания (ч. 1 ст. 47.1 Федерального конституционного закона «О Конституционном Суде Российской Федерации»).

Наконец, законодательная регламентация условий допустимости обращений позволяет по отношению к каждому из полномочий Конституционного Суда 
также выделить относящиеся к четвертой группе факты, подлежащие установлению при решении вопроса о возможности рассмотрения обращения по существу: например, применительно к абстрактному нормоконтролю - наличие «официально принятого решения федеральных органов государственной власти, высших государственных органов субъектов Российской Федерации или их должностных лиц» об отказе применять и исполнять оспариваемый нормативный правовой акт как не соответствующий Конституции Российской Федерации; наличие «официально принятого межгосударственным органом по защите прав и свобод человека решения, в котором констатируется нарушение в Российской Федерации прав и свобод человека при применении соответствующего нормативного акта или договора и необходимость внесения в них изменений, устраняющих отмеченные нарушения» (ч. 1 ст. 85 Федерального конституционного закона «О Конституционном Суде Российской Федерации») и др.; применительно к полномочию по рассмотрению жалоб на нарушение конституционных прав и свобод граждан - факты того, что оспариваемый закон затрагивает конституционные права и свободы непосредственно заявителя, что этот закон был применен в конкретном судебном деле, как правило, с участием заявителя, что рассмотрение дела было завершено в суде и др. (ч. 1 ст. 96 и ст. 97 Федерального конституционного закона «О Конституционном Суде Российской Федерации»); применительно к разрешению споров о компетенции - факт того, что спор не был или не может быть разрешен иным способом, факт соблюдения обязательного досудебного порядка урегулирования возникших разногласий и др. (ст. 93 Федерального конституционного закона «О Конституционном Суде Российской Федерации»).

Как свидетельствует практика, при принятии к рассмотрению запроса о толковании Конституции Российской Федерации имеет значение факт наличия действующего федерального закона, регулирующего те же отношения, что и конституционная норма, которую предлагается истолковать. Если подобный факт устанавливается Конституционным Судом, то он, как правило, отказывает в принятии к рассмотрению запроса: в данном случае необходимо ставить вопрос не о толковании Конституции, а о проверке конституционности соответствующего закона - одно полномочие Конституционного Суда не может подменять другое. Если же речь идет о том, что проект федерального закона лишь внесен или был принят в первом чтении, Конституционный Суд вправе принять к рассмотрению данный запрос, когда «поставленный в обращении о толковании Конституции Российской Федерации вопрос является принципиальным с точки зрения конституционной допустимости концепции, т.е. самой идеи, того или иного законодательного решения, а в понимании содержащихся в соответствующих нормах Конституции Российской Федерации предписаний - применительно к поставленному вопросу - действительно имеется неопределенность» (п. 2 мотивировочной части Постановления Конституционного Суда Российской Федерации от 1 июля 2015 года № 18-П).

Отдельно следует выделить юридические фaкmы, установление которых позволяет Конституционному Суду разрешить дело по сущуеству. Как уже отмечалось, применительно к полномочиям, связанным с нормоконтролем, эти факты имеют преимущественно вспомогательный характер, обосновывая правовую позицию сторон, а также Суда по делу. Конституционный Суд, в частности, устанавливает фактические обстоятельства:

связанные с историей разработки и принятия оспариваемого нормативного акта, в той мере, в какой они позволяют более точно уяснить намерения органа власти, связанные с предполагаемым характером правового регулирования, а значит, и более полно выявить волю, выраженную в соответствующих нормах;

касающиеся официального или иного толкования оспоренного законоположения, а также особенностей восприятия его содержания правоприменительной практикой, на что прямо ориентирует ч. 2 ст. 74 Федерального конституционного закона «О Конституционном Суде Российской Федерации». Особенно это касается полномочий, связанных с конкретным нормоконтролем, ибо они предполагают оценку оспариваемого закона именно в свете особенностей его применения;

относящиеся к порядку подписания, заключения, принятия, опубликования или введения в действие рассматриваемого акта, что позволяет оценить его конституционность по этим критериям.

Объем фактических обстоятельств, подлежащих установлению Конституционным Судом, зависит от специфики реализуемого им юрисдикционного полномочия. Некоторые из полномочий (например, толкование Конституции) могут практически не требовать установления фактов, другие (в частности, дача заключения о соблюдении установленного порядка выдвижения обвинения Президента Российской Федерации в государственной измене или совершении иного тяжкого преступления), наоборот, предполагают, прежде всего, установление фактических обстоятельств и по своей правовой природе тяготеют к обыч- 
ному судебному правоприменению. Отметим, что ч. 1 ст. 109 Федерального конституционного закона «О Конституционном Суде Российской Федерации» определяет и круг имеющих доказательственное значение документов, которые должны быть представлены в Суд для установления фактических обстоятельств по делу о соблюдении порядка выдвижения обвинения Президента Российской Федерации: к ним относятся текст решения о выдвижении обвинения, протокол или стенограмма обсуждения этого вопроса на заседании Государственной Думы и тексты всех связанных с этим обсуждением документов, а также текст заключения Верховного Суда Российской Федерации.

Федеральный конституционный закон «О Конституционном Суде Российской Федерации» непосредственно не устанавливает перечень фактических обстоятельств, не подлежащих доказыванию, в отличие от процессуальных кодексов, которые относят к таковым общеизвестные факты и факты, имеющие преюдициальное значение. При этом сам Конституционный Суд неоднократно подчеркивал, что решения суда общей юрисдикции имеют для него преюдициальное значение в вопросах установления фактических обстоятельств, ибо он не выполняет функции кассационной или надзорной инстанции по отношению к другим судам (Определение от 5 февраля 1998 года № 10-О и др.).

Федеральный конституционный закон «О Конституционном Суде Российской Федерации» (ст. 62-65) определяет круг возможных средств установления фактических обстоятельств, относя к ним объяснения сторон, заключения экспертов, показания свидетелей, документы. Данные нормы органично дополняются положениями Регламента Конституционного Суда Российской Федерации (параграфы 43-46). У каждого из этих средств имеется своя специфика и предназначение $[3,11]$.

Объяснение стороны имеет достаточно сложную структуру: оно включает правовые доводы, аргументы, т.е. выражает правовую позицию, содержит сведения о фактических обстоятельствах, обосновывающих данную позицию, в нем всегда проявляется волеизъявление соответствующего участника конституционного судопроизводства, иногда сопровождаемое определенными эмоциями. Объяснения сторон подлежат оценке в совокупности с иными источниками доказательств, но с обязательным учетом заинтересованности этих лиц в исходе дела.

Заключение эксперта является результатом профессионального исследования определенного судьей-докладчиком или Судом круга вопросов, выполняемого лицом, обладающим специальными познаниями в той или иной области науки, техники, искусства и т.д. Оно отличается от «консультаций специалистов», а также «разъяснений, консультаций и изложений профессиональных мнений по рассматриваемым делам», упоминаемых в законодательстве о конституционном судопроизводстве, которые представляют собой суждения по определенным, чаще всего, правовым вопросам.

Показания свидетеля используются, как прямо указано в ч. 1 ст. 64 Федерального конституционного закона «О Конституционном Суде Российской Федерации», исключительно «при необходимости исследования фактических обстоятельств, установление которых отнесено к ведению Конституционного Суда..». Документы являются материальными носителями различной правовой и фактической информации, необходимой для разрешения дела.

Следует обратить внимание на то, что порядок использования средств установления фактических обстоятельств зависит от организационной формы конституционного судопроизводства. При рассмотрении дел с проведением слушаний могут использоваться все вышеуказанные виды, а если дело рассматривается без проведения слушания - только документы, что обусловлено особенностями соответствующего процессуального порядка осуществления конституционного правосудия, реализация которого не связана с судоговорением.

В заключение отметим, что нередко сам фактор необходимости установления и исследования фактических обстоятельств воспринимается как обусловливающий невозможность отнесения того или иного полномочия к ведению Конституционного Суда. Это касается, в частности, проверки конституционности политических партий и иных общественных объединений. В качестве основания признания невозможным осуществления этого полномочия Конституционным Судом нередко указывают на то, что его реализация предполагает установление фактических обстоятельств, что не соответствует природе конституционного судопроизводства. С этим суждением вряд ли можно согласиться. Как указывалось выше, органы конституционного правосудия могут в отдельных случаях осуществлять полномочия, связанные с установлением таких обстоятельств. Важно лишь, чтобы они соответствовали предназначению судебного конституционного контроля и не «конкурировали» с полномочиями иных органов.

Признание политической партии неконституционной можно рассматривать как специфическую санкцию, применение которой «неразрывно связано с общим процессом реализации Конституции, требует 
конституционного истолкования положений соответствующих законодательных актов. Разрешение таких судебных дел в генеральном смысле имеет целью воплощение в государственно-правовой действительности важнейших конституционных принципов, обусловливающих взаимодействие между государством и гражданским обществом, участие политических партий и иных общественных объединений в осуществлении народовластия» [2]. Поэтому данные полномочия могут осуществляться посредством конституционного судопроизводства.
Исследуя фактические обстоятельства, связанные с допущенными партией и ее органами правонарушениями, конституционные суды вправе сделать обоснованный вывод: насколько значимы данные факты для оценки деятельности партии в целом, не придают ли они ей неконституционный характер. Об этом свидетельствует и зарубежный опыт: полномочиями по проверке конституционности политических партий наделены конституционные суды в Германии, многих странах Восточной Европы, а также СНГ (Азербайджан, Молдова и др.).

\section{Библиография:}

1. Бачернихина М.В. Состав техники установления фактических обстоятельств юридического дела // Вестник Владимирского юридического института. 2010. № 1. С. 61-63.

2. Брежнев О.В. Институт судебного контроля за законностью в деятельности общественных объединений в России: проблемы и перспективы развития // Конституционное и муниципальное право. 2012. № 6. С. 8-13.

3. Дедюкина И.С. Источники доказательств в конституционном судопроизводстве // Российский судья. 1999. № 2. С. 9-10.

4. Кожевников О.А. Некоторые проблемы в разграничении подведомственности споров между судами общей юрисдикции и конституционными (уставными) судами субъектов РФ и пути их разрешения // Право и политика. 2012. № 5. С. 897-901.

5. Кулапов В.Л., Сардаева О.Г. Современные проблемы установления фактических обстоятельств при квалификации противоправного поведения // Вестник Саратовской государственной юридической академии. 2015. № 1. С. 79-85.

6. Нарутто С.В. Конституционный судебный процесс: понятие, признаки, особенности // Право и политика. 2013. C. 708-713. DOI: 10.7256/1811-9018.2013.05.15.

7. Российский Б.В. К вопросу о конституционном судебном процессе как разновидности юридического процесса в Российской Федерации // Российская юстиция. 2012. № 6. С. 49-50.

8. Сергевнин С.Л. Конституционный нормоконтроль и отдельные общетеоретические проблемы судебного правотворчества // История государства и права. 2009. № 22. С. 6-10.

9. Тарибо Е.В. К вопросу об установлении и исследовании фактических обстоятельств в конституционном судопроизводстве (на примере налогообложения) // Российский юридический журнал. 2010. № 1. С. 7-18.

10. Шамшурин Л.Л. Достижение достоверного знания о фактических обстоятельствах дела // Российское правосудие. 2014. № 6. С. 18-32.

11. Шейнин Х.Б. Доказательства в конституционном судопроизводстве // Вестник Конституционного Суда Российской Федерации. 1996. № 6. С. 51-62.

12. Брежнев О.В. Кодекс административного судопроизводства Российской Федерации о разграничении подведомственности и особенностях взаимодействия между судами общей юрисдикции и органами конституционного правосудия // Административное и муниципальное право. 2015. № 6. С. 626 - 633. DOI: 10.7256/1999-2807.2015.6.15389.

13. Соколов Т.В. Сущность конституционного судопроизводства в контексте доктрины судебного права // Политика и Общество. 2014. № 2. С. 206 - 219. DOI: 10.7256/1812-8696.2014.2.11171.

14. Мокосеева М.А. Решения органов конституционной юстиции Российской Федерации: норма права или юридическая формальность // Административное и муниципальное право. 2015. № 9. С. 967 - 977. DOI: 10.7256/1999-2807.2015.9.16194.

\section{References (transliterated):}

1. Bachernikhina M.V. Sostav tekhniki ustanovleniya fakticheskikh obstoyatel'stv yuridicheskogo dela // Vestnik Vladimirskogo yuridicheskogo instituta. 2010. № 1. S. 61-63.

2. Brezhnev O.V. Institut sudebnogo kontrolya za zakonnost'yu v deyatel'nosti obshchestvennykh ob"edinenii v Rossii: problemy i perspektivy razvitiya // Konstitutsionnoe i munitsipal'noe pravo. 2012. № 6. S. 8-13.

3. Dedyukina I.S. Istochniki dokazatel'stv v konstitutsionnom sudoproizvodstve // Rossiiskii sud'ya. 1999. № 2. S. 9-10.

4. Kozhevnikov O.A. Nekotorye problemy v razgranichenii podvedomstvennosti sporov mezhdu sudami obshchei yurisdiktsii i konstitutsionnymi (ustavnymi) sudami sub"ektov RF i puti ikh razresheniya // Pravo i politika. 2012. № 5. S. 897-901.

5. Kulapov V.L., Sardaeva O.G. Sovremennye problemy ustanovleniya fakticheskikh obstoyatel'stv pri kvalifikatsii protivopravnogo povedeniya // Vestnik Saratovskoi gosudarstvennoi yuridicheskoi akademii. 2015. № 1. S. 79-85.

6. Narutto S.V. Konstitutsionnyi sudebnyi protsess: ponyatie, priznaki, osobennosti // Pravo i politika. 2013. № 5. S. 708-713. DOI: $10.7256 / 1811-9018.2013 .05 .15$.

7. Rossiiskii B.V. K voprosu o konstitutsionnom sudebnom protsesse kak raznovidnosti yuridicheskogo protsessa $\mathrm{v}$ Rossiiskoi Federatsii // Rossiiskaya yustitsiya. 2012. № 6. S. 49-50. 
DOI: $10.7256 / 1811-9018.2016 .9 .20089$

При цитировании этой статьи сноска на doi обязательна

Судебная власть

8. Sergevnin S.L. Konstitutsionnyi normokontrol' i otdel'nye obshcheteoreticheskie problemy sudebnogo pravotvorchestva // Istoriya gosudarstva i prava. 2009. № 22. S. 6-10.

9. Taribo E.V. K voprosu ob ustanovlenii i issledovanii fakticheskikh obstoyatel'stv v konstitutsionnom sudoproizvodstve (na primere nalogooblozheniya) // Rossiiskii yuridicheskii zhurnal. 2010. № 1. S. 7-18.

10. Shamshurin L.L. Dostizhenie dostovernogo znaniya o fakticheskikh obstoyatel'stvakh dela // Rossiiskoe pravosudie. 2014. № 6. S. 18-32.

11. Sheinin Kh.B. Dokazatel'stva v konstitutsionnom sudoproizvodstve // Vestnik Konstitutsionnogo Suda Rossiiskoi Federatsii. 1996. № 6. S. 51-62.

12. Brezhnev O.V. Kodeks administrativnogo sudoproizvodstva Rossiiskoi Federatsii o razgranichenii podvedomstvennosti i osobennostyakh vzaimodeistviya mezhdu sudami obshchei yurisdiktsii i organami konstitutsionnogo pravosudiya // Administrativnoe i munitsipal'noe pravo. 2015. № 6. C. 626 - 633. DOI: 10.7256/1999-2807.2015.6.15389.

13. Sokolov T.V. Sushchnost' konstitutsionnogo sudoproizvodstva v kontekste doktriny sudebnogo prava // Politika i Obshchestvo. 2014. № 2. C. 206 - 219. DOI: 10.7256/1812-8696.2014.2.11171.

14. Mokoseeva M.A. Resheniya organov konstitutsionnoi yustitsii Rossiiskoi Federatsii: norma prava ili yuridicheskaya formal'nost' // Administrativnoe i munitsipal’noe pravo. 2015. № 9. C. 967 - 977. DOI: 10.7256/1999-2807.2015.9.16194. 